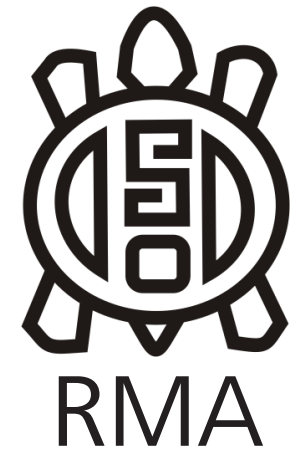

Dossier

\title{
Síntese dos estudos tecnológicos e macrotraceológicos em lâminas de machado lascadas de um grupo ceramista horticultor do Brasil
}

\author{
Synthesis of technological and macrotraceological studies on flaked \\ axe blades of a horticultural ceramist group in Brazil \\ Henry Luydy Abraham Fernandes*
}

* Programa de Pós-Graduação em Arqueologia e Patrimônio - Universidade Federal do Recôncavo da Bahia, Cachoeira, Bahia, Brasil. E-mail: luydyabraham@gmail.com

\begin{abstract}
Resumo
O objeto deste artigo são as lâminas de machado lascadas de sítios arqueológicos da Tradição Aratu do estado da Bahia, Brasil. Abordamos o contexto de afiliação cultural das peças, a sua distribuição geográfica e alguns dados cronológicos. No que diz respeito a sua produção, uma amostragem de 271 instrumentos é descrita e analisada pelo enfoque da tecnologia lítica. Por ele, são detalhadas as técnicas (percussão direta dura e picoteamento) e método (lascamento centrípeto bifacial) da produção, os estados técnicos e também as transformações em outros tipos de instrumentos. Já no que tange ao seu uso são estudados dentro da perspectiva da traceologia. Neste caso, concentramos as observações em três estigmas visíveis a olho nu: embotamento, brilho e estrias. De modo a compreender e comparar a formação dos estigmas de uso, realizamos várias experimentações controladas com réplicas cavando a terra e cortando árvores. Por meio deste estudo buscamos mostrar a constância do projeto mental tecnomorfológico do artefato, bem como a sua história de vida pela manutenção, versatilidade de uso e reconfigurações em outros objetos.
\end{abstract}

Palavras-chave: Experimentações arqueológicas; Traceologia macroscópica; Tecnologia lítica; Gerenciamento de instrumentos lascados; Pré-história da Bahia, Brasil.

\begin{abstract}
The object of this article is the flaked axe blades of archeological sites of the Aratu Tradition of the state of Bahia, Brazil. We address the cultural affiliation context of the pieces, their geographic distribution and some chronological data. With regard to their production, a sample of 271 instruments is described and analyzed by the lithic technology approach. Through it, the techniques (direct hard percussion and pecking) and method (bifacial centripetal flaking) of the production, the technical states and also the transformations in other types of instruments are detailed. About the use are studied from the perspective of the traceology. In this case, we concentrated the observations on three stigmas visible to the naked eye: rounding, brightness and striations. In order to understand and compare the formation of the stigmas of use, we performed several controlled experiments with replicas digging the ground and cutting trees. Through this study we seek to show the constancy of the technomorphological mental design of the artifact, as well as its maintenance, versatility of use and reconfigurations in other objects.
\end{abstract}

Keywords: Archaeological experiments; Traceology macroscopic; Lithic technology; Management of flaked instruments; Prehistory of Bahia, Brazil.

\section{Introdução}

Este artigo tem como objetivo mostrar a vida útil também entendida como história de vida - de um instrumento lítico lascado muito frequente e bem definido do ponto de vista tecnomorfológico, produzido por grupos ceramistas horticultores pré-históricos do estado da Bahia, Brasil. Nos referimos às lâminas de machados lascadas para as quais investigamos a produção, uso, desgastes, manutenção, quebras, esgotamento e descarte dentro de uma perspectiva que integra a tecnologia lítica, a traceologia e a experimentação arqueológica. 0 alcance deste estudo limita-se: - 1. geograficamente ao chamado Brasil Central (Fig 1), uma vasta amplidão que recobre vários estados do Brasil por onde os grupos em questão se expandiram; - 2. cronologicamente, a um período de aproximados 500 anos, do século IX ao século XIV da nossa era cristã e; - 3. culturalmente, a um grupo denominado pelos arqueólogos de Tradição Ceramista Arqueológica Aratu. Por último destacamos o alcance das observações traceológicas, tanto sobre os instrumentos arqueológicos como para os experimentais, que foram 
exclusivamente realizadas a olho nu. Sendo este o maior limitador destas investigações. Em que pese tal restrição, os instrumentos experimentais formaram uma coleção de referência que está disponível para futuras análises microscópicas, que sanarão essa lacuna momentânea.

O texto que aqui apresentamos é fruto do primeiro CAELA ( $1^{\circ}$ Congreso Argentino - Estudios Líticos en Arqueologia) realizado em Córdoba de 18 a 22 de setembro de 2018. Apresenta uma síntese dos estudos sobre os instrumentos mais representativos e numerosos da indústria lítica dos sítios arqueológicos da Tradição ceramista Aratu, concentrados no estado da Bahia, Brasil. Na qualidade de síntese, baseia-se, sobretudo, em sete publicações precedentes (FERNANDES, 2011b, 2012a, 2012b, 2014, 2017; FERNANDES e NASCIMENTO, 2015; FERNANDES, SILVA e NASCIMENTO 2015). Tais artigos derivam de um doutoramento não publicado (FERNANDES, 2011a) e discorrem sobre o aprofundamento de tópicos não esmiuçados durante o prazo de 4 anos da tese, inclusive com a inserção de novas coleções e a realização intensiva de experimentações.

No doutoramento (2011a) revisamos a bibliografia sobre o contexto dos sítios arqueológicos com lâminas de machados lascados no Brasil; descrevemos a morfologia e tecnologia destes instrumentos; apresentamos a cadeia operatória de produção e de reconfiguração das lâminas de machados lascados em outros instrumentos. Também discutimos sobre as então desconhecidas marcas de uso macroscópicas muito comuns nas coleções. Nos artigos subsequentes (FERNANDES, 2011b, 2012a, 2012b, 2014) reavaliamos os dados apresentados na tese; avançamos nos estudos das marcas macroscópicas de uso em instrumentos de outros sítios arqueológicos (FERNANDES e NASCIMENTO, 2015); estudamos lâminas de machado lascadas em rochas básicas - granito, diabásio e basalto também com marcas de uso macroscópicas (FERNANDES, SILVA e NASCIMENTO, 2015); e, em um reexame das variações dos sepultamentos (FERNANDES, 2017) citamos superficialmente a indústria lítica de produção de adornos em caulinita silicificada.

Para os contextos brasileiros destacamos a existência de um estudo (Mestrado) das marcas sobre instrumentos bifaciais lascados da região Sul e Nordeste da Argentina, notadamente conhecidos como bumerangóides, nos quais se detectou traços de uso macroscópicos cujos ensaios experimentais aos reproduziram cavando o solo (RODRIGUES, 2016). Novamente, ainda dentro da função de cavar o solo, indicamos a existência de um artigo centrado na região de Córdoba, Argentina, substancialmente correlato aos nossos trabalhos no Brasil, tanto por observar gumes com traços de desgaste nítidos a olho nu, como por realizar experimentações que mostram a tarefa de escavar a terra sendo responsável pelas marcas tão evidentes. As únicas diferenças residem na técnica das lâminas observadas, que foram polidas e não lascadas e no aporte da microscopia para a descrição dos desgastes. (MEDINA et al, 2019). Saindo do ambiente específico do Brasil e da Argentina e pensando em um escopo bibliográfico contextual existem publicações que englobam as perspectivas tecnológicas de instrumentos líticos traçando eventualmente interfaces com estudos funcionais (BOYDSTON, 1989; HAYDEN, 1989; STROULIA, 2003; GNECCO e ACEITUNO, 2004; POLITIS et al, 2008) que se complementam por outras obras voltadas especificamente para lâminas de machados ou enxós de pedra, quer pelo enfoque do uso, produção ou desgaste (CARNEIRO, 1979; TOTH et al, 1992; MILLS, 1993; GAERTNER, 1994; PAWLIK, 2006; BARKAI e YERKES, 2008; LUNARDI, 2008; GENESTE et al, 2010; TAKASHI, 2012; HISCOCK et al, 2016). Tais estudos servem de base para a reflexão sobre os contextos pouco conhecidos que estão por serem descobertos, envolvendo a produção/uso/manutenção/reciclagem/ descarte de lâminas lascadas ou polidas que existem nos sítios arqueológicos, preferencialmente entre os grupos horticultores.

\section{O contexto geral: a Tradição Ceramista Aratu}

No final dos anos 60, Valentim Calderón, um arqueólogo espanhol radicado no Brasil delimitou uma categoria da cultura material indígena caracterizada por recipientes cerâmicos sem decoração, pacote estratigráfico espesso e frequente presença de enterramentos primários em grandes urnas funerárias piriformes. Tendo em vista que o sítio chave para a identificação inicial deste conjunto encontrava-se nas margens da baia de Aratu (Estado da Bahia), o arqueólogo espanhol batizou esta cultura material de 'Tradição Aratu', seguindo a terminologia da corrente predominante em voga no Brasil (CALDERÓN, 1969). Posteriormente, outros pesquisadores ampliaram as informações a respeito da Tradição Aratu, reforçando o caráter espacial refletido em grandes aldeias anelares distribuídas por um amplo território no centro do país, com algumas ocupações de alta densidade populacional, chegando a 2.000 indivíduos (WÜST, 1983). A intensificação dos estudos facultou o conhecimento detalhado das formas dos recipientes cerâmicos, revelando uma intensa produção oleira ligada diretamente à subsistência horticultora (SCHMITZ et al, 1982). Por outro lado, com o avanço das escavações, o aspecto multiétnico de tais grupos humanos e seus contatos com outras populações veio à tona, o que permitiu compreender que seria inválido associar diretamente a cultura material chamada de Tradição Aratu a um único grupo ou a uma única população (GONZALEZ, 1996a, 1996b). Sem embargo, os vestígios encontrados representavam uma notável coerência material, todavia, foram produzidos por um contingente humano que inevitavelmente se transformou ao longo do tempo e dos deslocamentos de expansão pelo espaço.

Do ponto de vista geográfico, essa Tradição ocorre em 
todo o estado da Bahia, sugerindo que esta se trate da área central da ocupação. A oeste, surge em grande parte dos estados do Tocantins e Goiás; ao sul, está presente em todo o estado de Minas Gerais, do Espírito Santo e na porção norte do estado de São Paulo; para a região Nordeste há relatos de sítios em vários estados, sendo o limite setentrional atualmente conhecido no Ceará. Conforme aponta I. Wüst (1983), as zonas de floresta e de Cerrado são os lugares preferenciais das instalações, tendo em vista o potencial natural de fertilidade do solo para o cultivo. Não ocorrem no Pantanal, na região Sul do Brasil, nem na Floresta Amazônica. Assim sendo, de modo mais amplo, é possível identificar essa área da Tradição Aratu como uma grande mancha no centro-leste do país (Fig 1).

Do ponto de vista cronológico, até 2014 havia apenas seis datações confiáveis por carbono 14 disponíveis para o estado da Bahia que situam a Tradição Aratu em um intervalo de 490 anos, entre o século IX e o XIV da era cristã: $1080 \pm 90$ - Guipe; $900 \pm 250$ - São Desiderio; $870 \pm 50$ - Piragiba; $770 \pm 50$ - Sauipe; $660 \pm 30-$ Água Vermelha; $590 \pm 40-$ Beliscão (Fig 1). Após, esse período a Tradição Aratu como a conhecemos teria se extinguido ou se transformado a tal ponto de não ser mais reconhecida conforme os padrões estabelecidos (FERNANDES, 2017).

Até aproximadamente os anos 2000, os estudos sobre as indústrias líticas dos grupos ceramistas horticultores eram marginalizados pelos cientistas brasileiros. Os relativamente poucos enfoques de análises tecnológicas centravam-se nos conjuntos líticos dos caçadorescoletores e praticamente inexistiam abordagens no campo da traceologia. Entretanto, incontáveis sítios arqueológicos de povos ceramistas horticultores guardam em sua estratigrafia um volumoso espólio de pedras lascadas e polidas aptas para tais investigações. Os assentamentos da tradição Aratu não são diferentes. De fato, o sítio de Piragiba passou por uma expressiva coleta de artefatos dando oportunidade para um conhecimento mais aprofundado, inicialmente dos seus sepultamentos e depois da sua indústria lítica.

\section{O sítio arqueológico de Piragiba}

Conforme o dito acima, a base para as nossas investigações sobre a tecnologia lítica dos grupos ceramistas e horticultores da Tradição Aratu está na coleção derivada das pesquisas no sítio arqueológico de Piragiba, localizado no Oeste do estado da Bahia, Brasil. Esse relevante conjunto de vestígios materiais indígenas repousa exatamente sob a atual vila de Piragiba, donde se origina a sua designação (Fig 1). Aliás, foi a instalação e crescimento da vila a partir do final do século XIX que deflagrou um processo de desmatamento e erosão do solo responsável por revelar o sítio arqueológico.
Relata Fernandes (2003) que entre 1996 e 1997 uma equipe da Universidade Federal da Bahia, coordenada pelo professor arqueólogo argentino radicado no Brasil, Carlos Etchevarne, escavou uma parcela dos vestígios da grande aldeia indígena datada em $970 \pm 50$ AP (GIF10999, sepultamento humano. Não calibrado), cujos testemunhos materiais afloravam em uma área com cerca de $350.000 \mathrm{~m}^{2}$ (700 x $500 \mathrm{~m}$ ). Esta superfície englobava quase todas as casas, os quintais e a praça da atual vila. Tal pesquisa revelou mais de 120 sepultamentos primários em urnas funerárias, outros oito em decúbito e fletidos, bem como um acervo lítico lascado superior a 12.000 peças. A imprecisão dos números reside no fato de que a cada nova estação chuvosa, de novembro a março, mais urnas, fragmentos cerâmicos e objetos líticos surgem no solo do sítio. As especificidades da cerâmica e a forma dos enterramentos apontaram claramente para a Tradição Aratu, que corresponde a populações indígenas estáveis, sedentárias, que dominaram o centro do Brasil e desapareceram antes da ocupação europeia lusitana, a partir de $1.500 \mathrm{AD}$.

Dentro do conjunto lítico, obteve destaque um tipo particular de instrumento: as lâminas de machado lascadas, que somavam mais de 500 exemplares (Fig 2). As centenas destas lâminas pareciam, logo a primeira vista, bastante padronizadas. Além disso, o gume de várias delas apresentava um aspecto brilhante, em maior ou menor grau, dando a impressão de uma abrasão e delicado polimento. Foi justamente essa característica particular que desencadeou a progressão dos estudos direcionados a uma visão mais detalhada e abrangente sobre a produção, uso, manutenção e descarte daqueles utensílios. Tal intento concretizou-se inicialmente pela elaboração de um doutoramento (FERNANDES 2011a) quando focamos uma amostra de 271 lâminas de machado lascadas. Desta produção também derivaram alguns artigos com o viés voltado para a traceologia. Desta forma, a intenção do presente artigo é divulgar as investigações que envolvem a compreensão do que pode ser entendido como a vida útil das lâminas de machado lascadas, dentro de uma perspectiva integrada.

\section{O que são as lâminas de machados lascadas?}

As poucas referências localizadas na bibliografia brasileira versando sobre lâminas de machados lascadas apontavam para instrumentos totalmente inesperados pela fragilidade das rochas aptas ao lascamento (predominantemente o sílex), tidos como pré-formas de polidos, esboços ou peças inacabadas (PROUS et al, 1994), muito frágeis para o uso, resultados do treinamento do lascamento bifacial ou ainda objetos abandonados por quebra na produção (PROUS et al, 1996/97). Em um dos primeiros manuais em português relativo à análise de achados líticos (LAMING-EMPERAIRE, 1967), obra que serviu de referência obrigatória a várias gerações de arqueólogos brasileiros, a autora considerava as lâminas de machados 

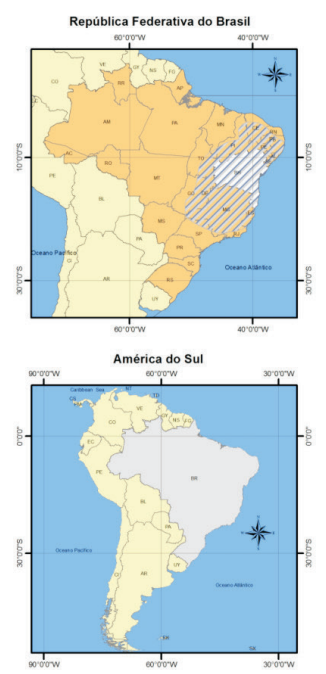

ÁREA DA TRADIÇÃo ARATU 2019

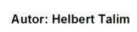

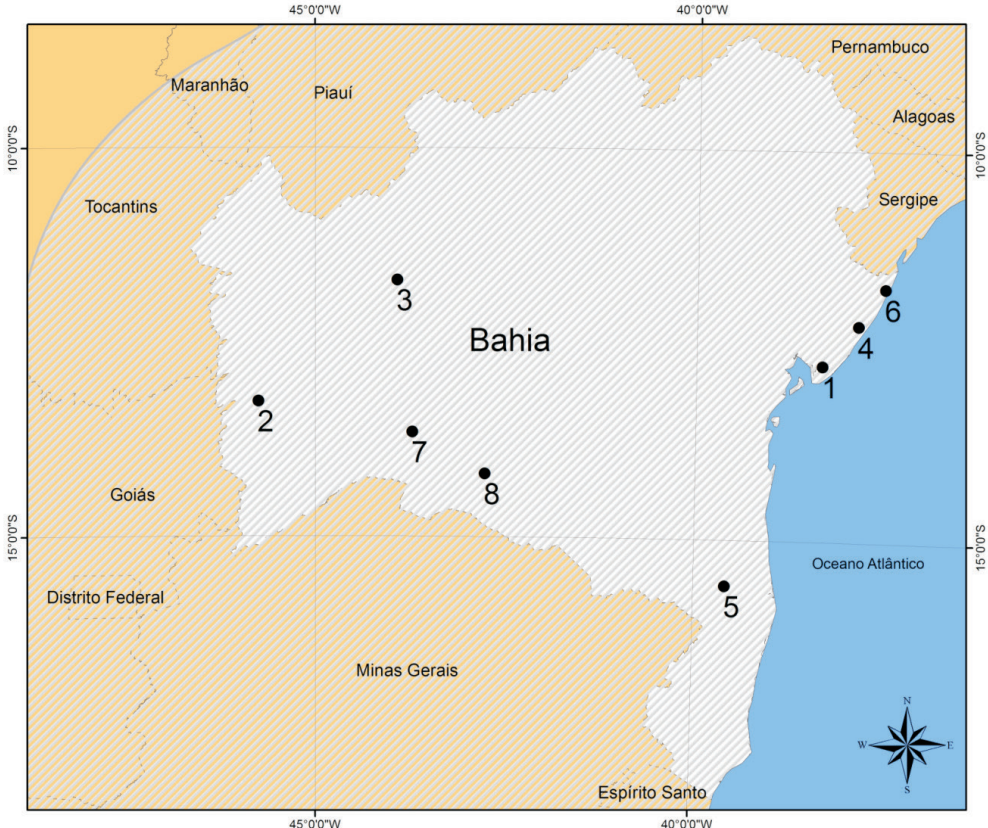

$40^{\circ} 0^{\circ} \mathrm{ow}$

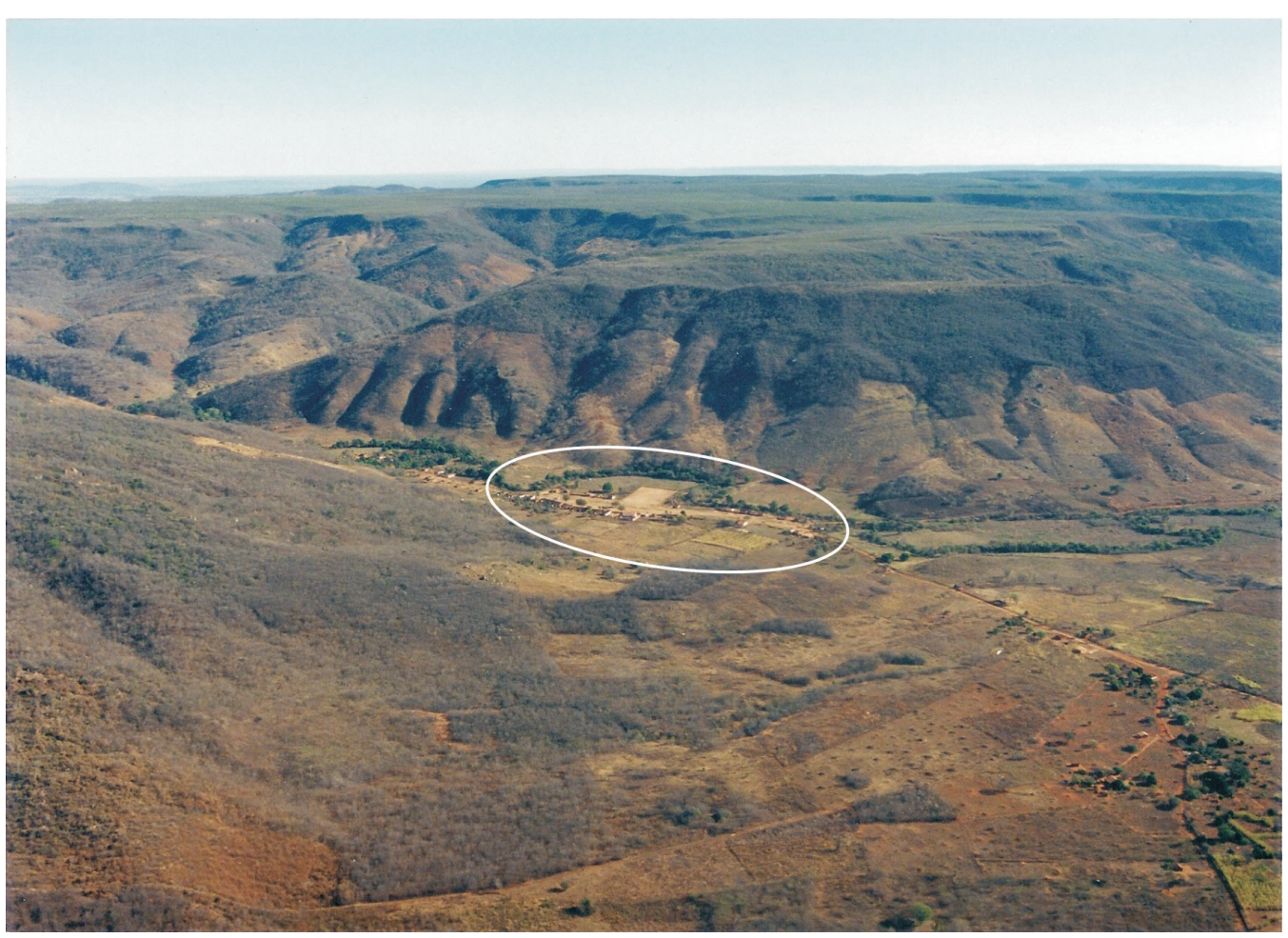

Figura 1. Área ocupada pela Tradição Arqueológica Aratu no Brasil. Sítios arqueológicos no estado da Bahia citados neste artigo: 1. Guipe; 2. São Desidério; 3. Piragiba; 4. Sauípe; 5. Água Vermelha; 6. Beliscão; 7. BA-RC-44; 8.Coité. Vista aérea da vila de Piragiba. O sítio arqueológico está delimitado aproximadamente pela elipse. Sobrevoo de 2001.

Figure 1. Area occupied by Aratu Archaeological Tradition in Brazil. Archaeological sites in the state of Bahia cited in the article: 1. Guipe; 2. São Desidério; 3. Piragiba; 4. Sauípe; 5. Água Vermelha; 6. Beliscão; 7. BA-RC-44; 8. Coité. Aerial view of the village of Piragiba. The archaeological site is approximately delimited by the ellipse. 2011 flyover. 
lascadas um instrumento pouco comum na América do Sul.

As primeiras descrições genéricas para lâminas de machados lascadas constam do supracitado manual e distinguem duas faces nas quais são observados o gume, o talão e os flancos (LAMING-EMPERAIRE, 1967). Dos anos 90 provém a maior coleção até então conhecida (50 exemplares, sítio BA-RC-44, Bahia. Fig 1) destes utensílios, cuja descrição alia elementos morfológicos a indicadores tecnológicos, aludindo às técnicas do lascamento e do picoteamento (SCHMITZ et al, 1996). Na literatura, vários são os termos empregados para descrever as lâminas: - amigdalóies, trapezoidais irregulares (CALDERÓN, 1971); - petalóides (SCHMITZ et al, 1996). Estes termos denunciam o caráter morfo-dinâmico dos instrumentos em questão. Se nenhum dos termos pode ser descartado, nenhum deles abrange o processo no seu todo, sendo as relações entre as partes do instrumento e entre as técnicas de produção de cada uma das partes, assim como a sua gestão, que devem ser enfocadas para compreender e descrever esse objeto, realizando o salto teóricometodológico do formal para o tecnológico.

Pensando desta maneira, definimos (FERNANDES, 2011b) as lâminas de machados lascadas de Piragiba recorrendo a dois aspectos: -1. o tecnológico, e fruto deste, -2. o morfológico. -1. No que tange ao morfológico (Fig 2), são instrumentos de duas faces, delimitadas por dois flancos laterais. Tais flancos opõem em um dos seus extremos, um gume ativo (quase sempre mais largo) e no outro extremo convergem para o talão preênsil/passivo (geralmente mais estreito). A silhueta pode delinear muitos contornos, a depender do estágio técnico do utensílio. O traçado do gume pode variar, porém tende a ser perpendicular ao eixo longitudinal do instrumento. De modo geral, se fôssemos classificar as formas, veríamos variações de módulos volumétricos mais ou menos achatados, com delineamentos subtriangulares ou subtrapezoidais alongados. As dimensões enquadram-se entre o máximo de $18 \mathrm{~cm}$ e um mínimo de $6 \mathrm{~cm}$, sendo que a maior parte delas tem por volta de $10 \mathrm{~cm}$. -2 . Quanto ao aspecto tecnológico, são instrumentos lascados bifacialmente, tendo como suportes grandes lascas (mais frequente) ou mesmo seixos (mais raro). A façonagem nos flancos é realizada pela intercalação da percussão direta dura e do picoteamento, ambas as técnicas retiram séries de lascas mais ou menos largas e curtas. No gume, uma ou duas sequências de lascamentos sobrepostas configuram e delineiam o fio. O picoteado está presente de modo recorrente nos flancos e no talão. Eventualmente, também nas faces e arestas é aplicado esse típico tratamento picoteado. Raramente toda a superfície do instrumento se mostra regularizada dessa forma.

Segundo constata Fernandes (2011b), a constância na articulação espacial, tecnológica e morfológica permite reconhecer uma lâmina de machado lascada ao longo da sua vida útil, pois a relação entre essas partes: faces, gume, flancos e talão, assim como as técnicas aplicadas nelas se mantêm. Essa constância na imagem mental faculta identificar transformações morfotecnológicas do instrumento, quer por uso, quer acidentalmente, quer por transformação radical intencional da sua estrutura e funcionalidade. Nesse caso, a relação entre o gume, os flancos e o talão é literalmente quebrada. Contudo, tanto os indicadores tecnológicos dessa primeira produção das partes (faces, gume, flancos e talão), como alguns sinais de uso do instrumento durante a sua primeira configuração (embotamento, brilho e estrias) ainda podem ser encontrados no novo utensílio. Essas reminiscências tecnológicas e/ou essa retenção de sinais de uso permitiu traçar a 'evolução' de alguns exemplares e compreender suas transformações mais brandas e mais radicais no decurso das suas vidas úteis. Em certos casos,
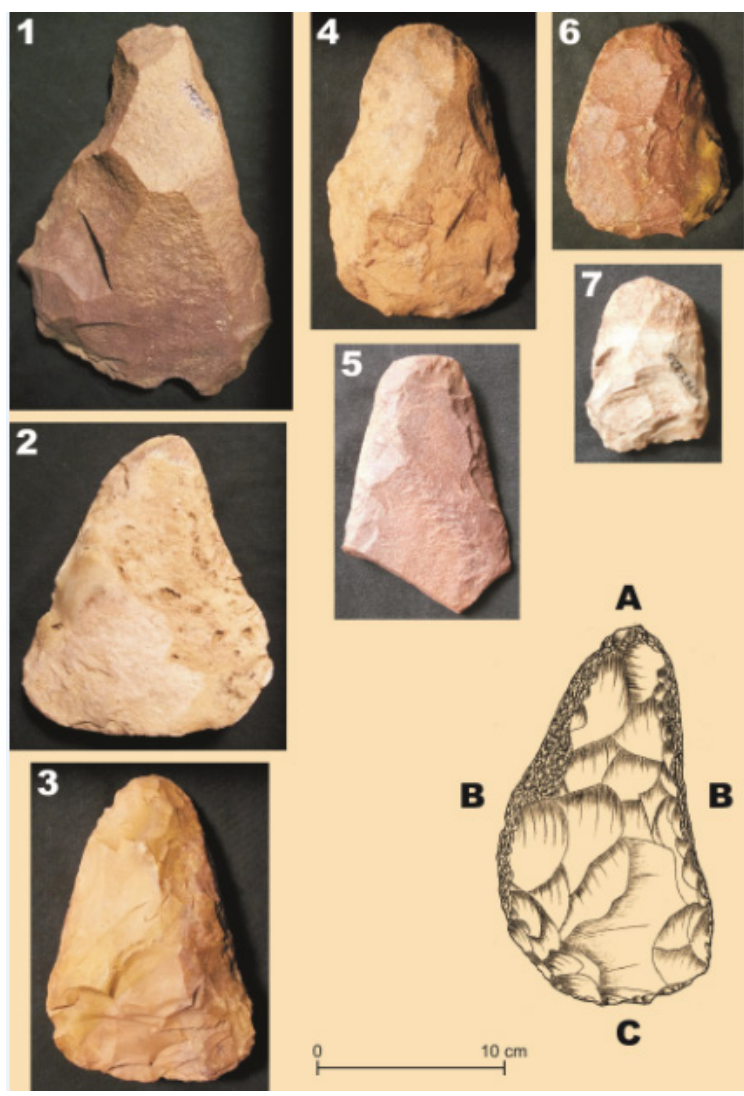

A

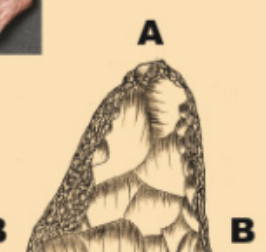

Figura 2. Lâminas de machado lascadas da Tradição Aratu. 1. Inacabada; 2 . Recém-terminada; 3 e 4 . Pouco reavivada; 5. Gume parcialmente quebrado; 6. Reestruturada; 7. Esgotada. Nomenclatura das partes do instrumento e técnicas aplicadas. A. Talão: lascado e picoteado; B. Flancos: lascados e picoteados; C. Gume: lascado.

Figure 2. Flaked axe blades of Tradition Aratu. 1. Unfinished; 2. Newly terminated; 3 and 4. Little revived; 5. Partially broken edge; 6. Restructured; 7. Exhausted. Nomenclature of parts of the instrument and techniques applied. A. Butt: flaked and pecked; B. Flanks: flaked and pecked; C. Edge: flaked. 
por essa lógica detectamos o percurso que levou algumas lâminas de machado lascadas a serem convertidas em instrumentos completamente diferentes.

\section{Como foram produzidas as lâminas de machado lascadas?}

As matérias-primas preferenciais para a fabricação das lâminas nos sítios investigados são, em ordem decrescente de frequência: - o arenito silicificado; o sílex; - a calcedônia; - o granito. Instrumentos nesta última rocha são conhecidos, por enquanto, apenas nos sítios do município de Palmas de Monte Alto, Bahia (Fig 1), especialmente no sítio Coité (FERNANDES, SILVA, NASCIMENTO, 2015). Via de regra, as fontes primárias e secundárias estão sempre muito próximas aos sítios e os restos dos lascamentos tendem a ser abundantes no espaço de habitação.

A maioria dos instrumentos é executada sobre lascas suporte* (termos marcados por * são definidos no Léxico Terminológico de Inizan et al (1995)), sendo uma parcela menor realizada sobre seixos, conforme o neocórtex* residual permite diagnosticar. A debitagem*, ou seja, a retirada intencional do suporte para o instrumento ocorre pela técnica da percussão direta dura*. Em seguida, a façonagem* desenvolve-se com a mesma técnica em uma sucessão de golpes concêntricos sobre o suporte, começando a delinear o gume, flancos e talão da lâmina de machado. A segunda técnica usada na configuração das lâminas é o picoteamento*. Preferencialmente o talão e os flancos são picoteados. Eventualmente algumas arestas* e nervuras* das faces podem ser atenuadas por essa técnica. Ao longo da façonagem, tanto o lascamento como o picoteamento se alternam de modo a criar no objeto a forma desejada, isto é, um gume mais largo, idealmente em arco e com ângulos ao redor de $80^{\circ}$, em contraste a um talão mais estreito, robusto e volumoso. Tal preparação e morfologia, significativamente intensa e demorada no talão, se prestariam a acomodar o instrumento em um cabo, conforme mostraram zonas com brilho sobre o picoteamento. O retoque* pode ou não ser aplicado no gume, a depender do cuidado com que o seu fio foi delineado durante a façonagem. Em todo o caso, pelo que os exemplares arqueológicos apontam, o contorno buscado para os gumes corresponde aos fios mais eficazes até a atualidade para tais instrumentos, ou seja, os mesmos fios ligeiramente curvos ou convexos dos machados de ferro modernos (FERNANDES, 2014).

Em virtude da intercalação do lascamento e do picoteamento intensivo na façonagem das lâminas de machado surgem várias lascas e outros indicadores que são restos típicos diagnósticos da produção destes instrumentos (Fig 3). Trata-se de lascas geralmente mais largas que longas, com talão picoteado, ocasionalmente parte da face superior* também picoteada, com duplo ou até triplo ponto de impacto* e respectivos bulbos*, além de nervuras acessórias incompletas visíveis na face inferior* separando os pontos de impacto. Também podem surgir muitas fissuras de golpes anteriores do picoteamento (FERNANDES, 2011b). Quando as lascas do flanco ou talão são pequenas (cerca de $2 \mathrm{~cm}$ ou menos) tendem a se quebrar transversalmente. A parcela proximal retém os estigmas diagnósticos apontados enquanto que a parte distal não conserva nenhum dos atributos indicados acima. Ainda que não se localizem os instrumentos, o achado de lascas com tais estigmas permite aventar a possibilidade da produção de tais lâminas graças à peculiaridade destes seus estigmas.

\section{A vida útil das lâminas de machado lascadas}

Conforme constata Fernandes (2011a), desfechado o último golpe do percutor o instrumento recém-terminado está pronto para o uso. A partir de então, se submeterá a outros intensos choques, desta vez agindo sobre as matérias para as quais foi concebido. A relativa fragilidade das rochas silicosas (arenito silicificado, sílex e calcedônia) de que foram feitos, se comparada à resistência das rochas comuns para as lâminas polidas (granito, basalto e diabásio, por exemplo), justifica a relutância encontrada na bibliografia para considerar tais instrumentos como lâminas efetivas e finalizadas. É exatamente essa fragilidade na matéria-prima, aumentada pelas fissuras provocadas pelo picoteamento insistente na produção e somada ao manejo intenso, que levam esses instrumentos a perderem massa paulatinamente durante sua vida ou até mesmo a se fragmentarem, tornando-se imprestáveis. Talvez essa fragilidade seja uma das explicações plausíveis para o número tão elevado de lâminas de machado lascadas encontrado no sítio de Piragiba.

Como a coleção de Piragiba é bastante numerosa permitiu o estabelecimento de alguns estágios técnicos para os instrumentos coletados naquele e em outros sítios similares. Assim, foram estabelecidas seis etapas dentro de uma lógica de desgaste e de necessários reavivamentos* do gume: -1 . inacabados; 2 . recémterminados; -3 . pouco reavivados; -4 . gumes parcialmente quebrados; -5. reestruturados; -6. esgotados (Fig 2).

- Instrumentos inacabados são extremamente raros e estão representados por peças que não têm a delimitação final do gume, não mostrando o típico tratamento do picoteado nos flancos e no talão.

- As peças recém-terminadas têm o fio do gume completamente intacto, com o delineamento e o ângulo ideais, projetados pelo lascador. Dentro da coleção estas são as peças mais raras, pois se destinavam ao imediato uso e não ao descarte.

- As peças cujos gumes estão pouco reavivados testemunham o início da vida funcional do instrumento. Sendo de uma rocha frágil e tendo no seu gume o 

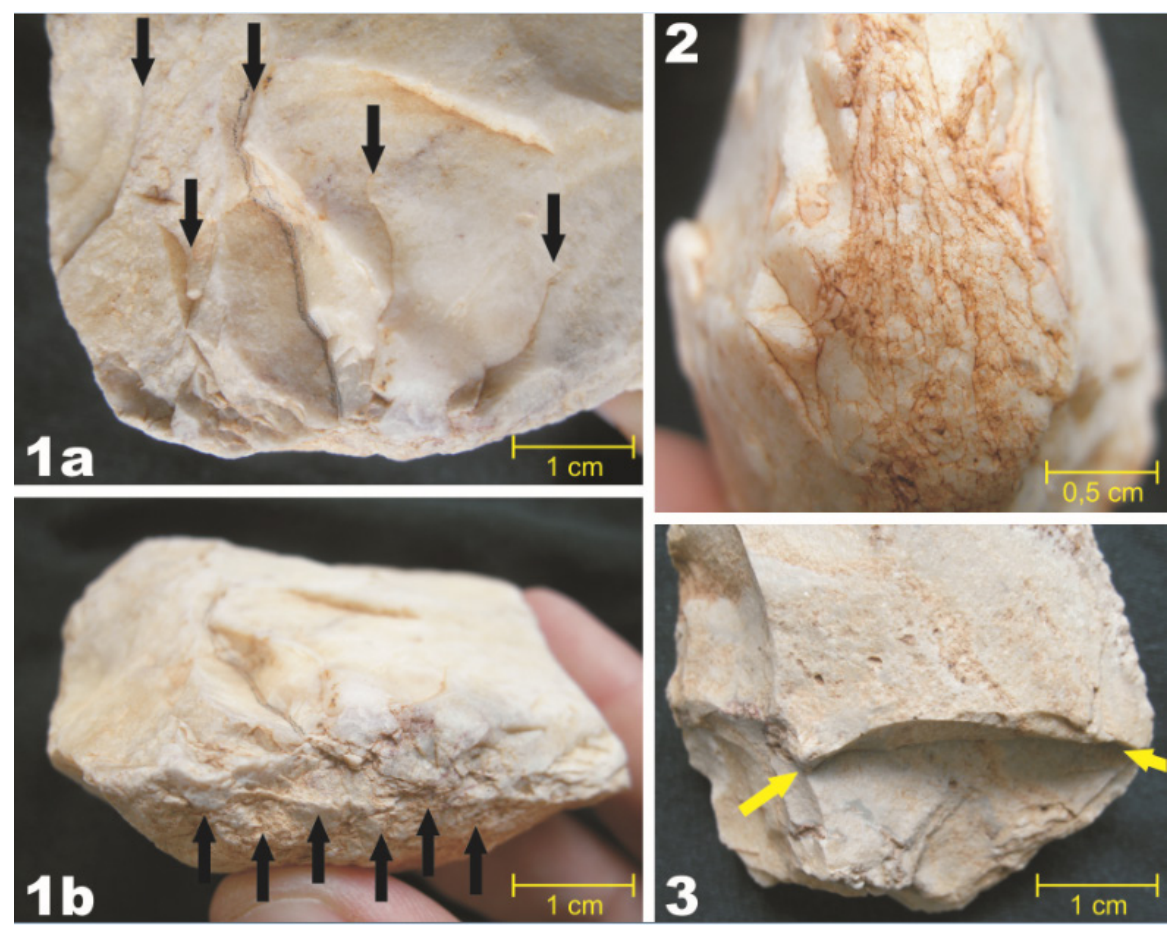

Figura 3. Face inferior (1a) e talão (1b) de lasca típica do flanco das lâminas de machado. 1a. Setas pretas indicam as nervuras acessórias. $1 \mathrm{~b}$. Setas pretas indicam o picoteado no talão. 2. Detalhe do talão picoteado de uma lâmina de machado lascada. 3. Negativo de retirada de uma lasca com quebra transversal delimitado pelas setas.

Figure 3. Lower face (1a) and butt (1b) typical flake of flank of the axe blades. 1a. Black arrows indicate the accessory veins. $1 \mathrm{~b}$. Black arrows indicate the pecking on the butt. 2. Detail of the pecked butt of a flaked blade. 3. Negative of removal of a flake with cross-breaking delimited by the arrows. ângulo mais agudo de todo o objeto, este é o primeiro a sofrer perdas. É exatamente por tais perdas que também podemos estipular uma trajetória de uso.

- As peças com o gume parcialmente quebrado atestam os primeiros grandes acidentes sofridos pelo instrumento. A fratura mais comum é do canto do gume, donde se destaca uma grande lasca subtriangular que geralmente retém o trecho onde se encontram a parte distal do flanco picoteado e um dos cantos do gume lascado. V. Calderón (1971) encontrou vários fragmentos de canto de gume de lâminas de machado lascadas nos sítios pesquisados por ele no Oeste da Bahia. Desconhecendo as bases da análise tecnológica, identificou-os a partir de uma premissa morfológica como raspadores semicirculares.

- As peças reestruturadas são fruto do relascamento de um gume quebrado, de tal maneira que o novo gume mantenha-se desempenhando a mesma função para a qual o instrumento foi projetado, isto é, continue sendo uma lâmina de machado lascada. Notadamente, essa lâmina reestruturada tem massa e dimensões bem menores que as iniciais, apontando para o seu avanço pela meia idade do instrumento. É interessante observar que mesmo na meia-vida, o seu gume agora está temporariamente livre de marcas de uso pelo relascamento da reestruturação. Assim sendo, os relascamentos de reestruturação também produzem lascas típicas desta indústria que terão marcas de uso (embotamento, brilho, estrias) nas suas superfícies.

- Por último, as peças esgotadas atingem o fim da vida útil do instrumento pela total impossibilidade de reconstituição do gume. A escassa massa restante inviabiliza a manutenção do utensílio que é descartado.
Tais exemplares são os mais abundantes na coleção, comprovando um alto índice de produção e de desgaste destas lâminas.

\section{As marcas de uso nas lâminas de machado lascadas}

A presença de marcas de uso nas lâminas de machado lascadas, sobretudo o brilho intenso (Fig 4), também foi uma surpresa por representar um atributo até então desconhecido no Brasil (FERNANDES, 2003, 2012b; FERNANDES, SILVA e NASCIMENTO, 2015). Além do brilho, também se mostravam de forma eloquente o embotamento e as estrias. Em princípio, todos os arqueólogos consultados imputaram os estigmas de desgaste nos instrumentos a agentes naturais, tais como o fluxo de água ou o lustre de solo. Contrapomos tal interpretação a partir dos argumentos sobre: - a quantidade de artefatos com o brilho; - a localização desse sinal preferencialmente nos gumes dos artefatos; - a ausência de fluxo de água no local de coleta de algumas das lâminas; - a associação do brilho com outras marcas de uso, tais como embotamentos e estrias; - a existência de diferentes graus de brilho em sequências de lascamentos de reavivamento do gume; - a presença de brilho em lâminas de machados lascadas de outro sítio não sujeito a cheias.

A veemente refutação das marcas de uso macroscópicas por parte dos arqueólogos brasileiros consultados impeliu-nos a elaborar um programa de experimentação visando replicar aquelas notáveis marcas em reproduções dos instrumentos lascados. Para tanto, recolhemos no sítio de Piragiba o sílex e o arenito silicificado e no sítio de Coité o granito. Com tais matérias-primas produzimos os instrumentos experimentais seguindo as mesmas 
técnicas e métodos vistos nos artefatos arqueológicos. Como supúnhamos que as atividades básicas para a subsistência de grupos indígenas horticultores préhistóricos eram: - cortar madeira e - preparar o solo para o cultivo, estipulamos estas duas atividades no protocolo experimental. Após os testes iniciais, fixamos sequências contínuas de 200 golpes para o corte de madeira verde e de 400 golpes para o revolvimento do solo. Entre estas sequências os instrumentos eram observados e a formação dos estigmas de desgaste registrada com fotos.

Tentamos trabalhar sem encabamento, o que se mostrou inviável tanto pela pouca efetividade na penetração do gume como pela mágoa causada às mãos. Assim sendo, optamos por fixar as lâminas em cabos de madeira. Para tanto, foi entalhado um nicho para o encaixe do talão das lâminas nos cabos. Os instrumentos líticos eram ainda amarrados com barbante de algodão, sem aplicação de resina, de modo a facilitar a retirada da peça para as análises e fotografias. Tal cuidado também permitiu constatar a formação de brilho sobre o picoteado na parte preênsil das lâminas. As madeiras empregadas para os cabos foram a mangueira - gênero Mangifera e a jurema - gênero Mimosa (DOURADO et al, 2013). Dadas às leis de proteção da flora, somente tivemos autorização para o corte destas duas árvores, tanto para a obtenção dos cabos, como para a execução das experimentações traceológicas. Seguramente, os grupos humanos do passado dispunham de uma gama impensável de madeiras as quais testavam e selecionavam pela sua maior aptidão ao trabalho desejado.

O programa estipulado controlava as variáveis do - tempo, - número de golpes, - matéria trabalhada (madeira ou terra) e - forma de encabamento (gume paralelo ao cabo, como num machado; gume perpendicular ao cabo, como numa enxada). Pela bibliografia da área (URQUIJO e ESTEVEZ, 1994; TRIAS, 2007) é de costume cronometrar o tempo em experimentações de uso de instrumentos líticos. Sem embargo, experimentadores diferentes têm ritmos de trabalho e forças distintas e isso afetaria a velocidade e intensidade das alterações nos gumes em um mesmo intervalo de tempo. Tendo em vista esta discrepância, preferimos também inserir o controle do
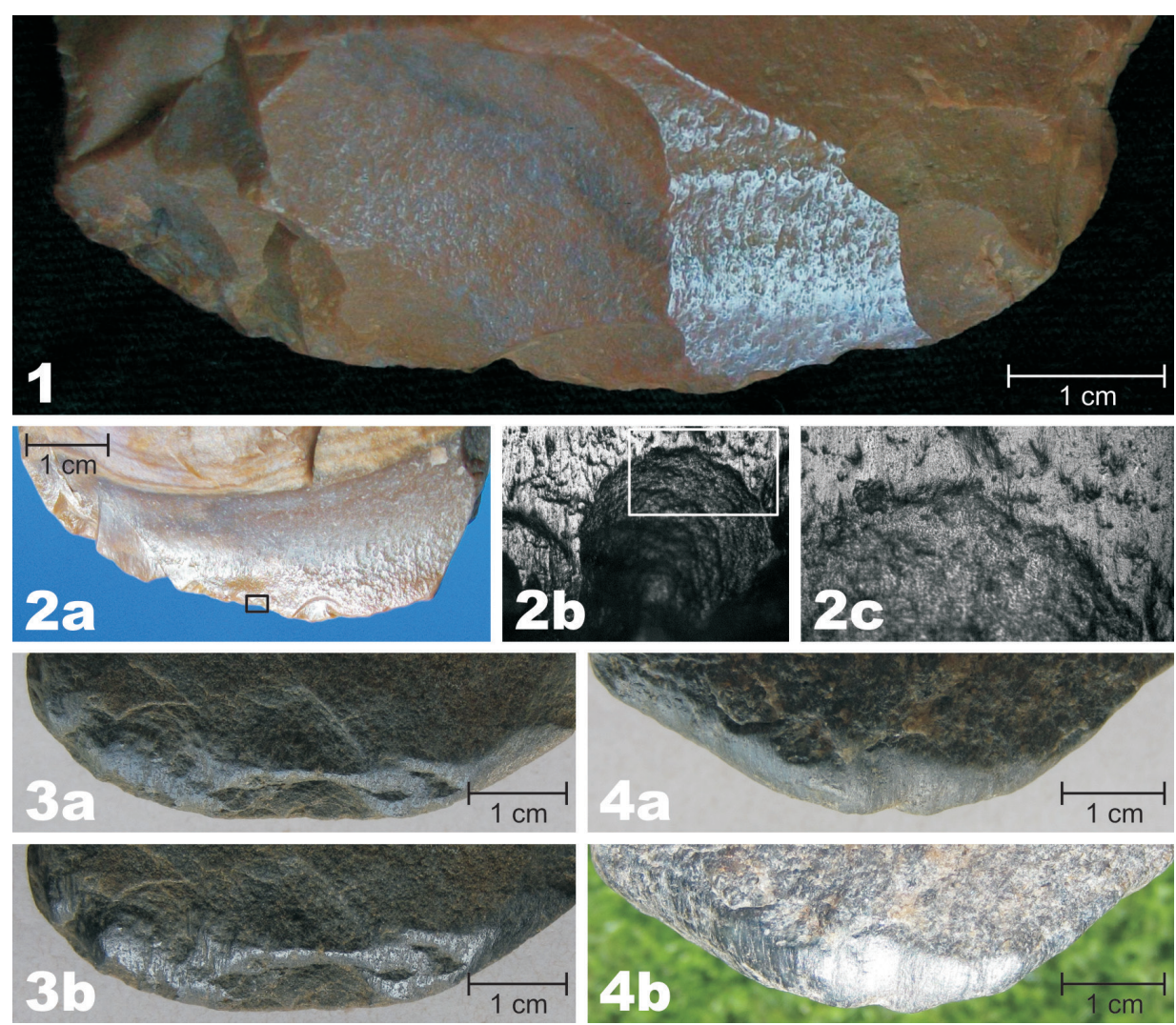

Figura 4. 1. Brilho e estrias no gume de uma lâmina de machado lascada arqueológica em sílex. 2abc. Brilho e estrias no gume de uma lâmina de machado experimental em silex: cavar terra / 28 mil golpes / 3 horas e 50 minutos. 2b. Detalhe a 50 aumentos. 2c. A 100 aumentos. 3ab. Brilho e estrias no gume de uma lâmina de machado lascada arqueológica em granito. 4ab. Brilho e estrias no gume de uma lâmina de machado experimental em granito: cavar terra / 20 mil golpes / 2 horas, 2 minutos e 41 segundos.

Figure 4. Gloss and striations on the edge of a flaked axe archaeological flint blade. 2abc. Gloss and striations on the edge of an experimental axe blade: digging earth / 28,000 strokes / 3 hours and 50 minutes. 2b. Detail to 50x magnification. 2c. At 100x magnification. 3ab. Gloss and striations on the edge of a blade of axe flaked archaeological in granite. 4ab. Gloss and striations on the edge of an experimental axe blade: digging earth / 20,000 strokes / 2 hours, 2 minutes and 41 seconds. 
número de golpes, pois se trata de uma maneira menos insegura de reproduzir e de comparar os ensaios.

Dentre as dez reproduções de lâminas de machado lascadas cinco concederam resultados satisfatórios para o acompanhamento da formação dos estigmas de desgaste da superfície rochosa. As outras cinco também apresentaram marcas equivalentes, contudo problemas com as peculiaridades visuais da superfície da matéria impediram a realização de fotografias que permitissem visualizar os macrotraços de uso. Na tabela 1 abaixo resumimos as características dos instrumentos experimentais, os parâmetros e resultados das experimentações.

\section{Avaliação das experimentações}

Os golpes desfechados com um machado atual penetram profundamente na madeira, arrancado cavacos que são projetados à distância. As lâminas polidas em rochas básicas resistem bem a impactos semelhantes, embora fendam a madeira com menor efetividade. Por sua vez, o manejo de uma lâmina de machado lascada é bastante diferente do manuseio de uma lâmina de ferro moderna. Se o indígena pré-histórico agisse da mesma forma, desferindo um golpe com igual força e velocidade, imediatamente fragmentaria a sua lâmina de machado lascada, arrebentando-a por completo. Foi precisamente o que notamos nas experimentações e também o que viu J. Iversen (1956) quando conduziu lenhadores profissionais da Dinamarca no corte de árvores com lâminas de sílex. Portanto, os golpes com machados de lâminas lascadas em rochas frágeis precisam ser relativamente brandos, curtos e cautelosos. O indígena deve conhecer empiricamente o sutil limite entre o máximo de força empregada e o ponto crítico de resistência da rocha, de modo a não ultrapassá-lo. Ainda assim, a acumulação dos impactos com o passar do tempo leva a inevitável fadiga da rocha e conseguinte ruptura do instrumento arqueológico.

Feitas as ressalvas sobre a cinemática do uso, a primeira constatação causou surpresa. De maneira clara, cavar a terra produziu marcas de uso idênticas em matériasprimas tão diversas como o sílex muito fino, o arenito fino ou grosso e o granito grosso. Em instrumentos dessas rochas as marcas macroscópicas de uso (embotamento, brilho e estrias) revelaram-se coincidentes, muito visíveis e ostentando grandes dimensões. Aliás, ao atentarmos para as atuais lâminas metálicas de enxadas também constatamos marcas de utilização de aspecto muito similar àquelas nas rochas. Talvez a intensidade do uso da ferramenta contra as poderosas partículas abrasivas componentes da terra provoque um mecanismo de corrosão muito convergente, quer seja sobre as várias rochas, quer seja até sobre os metais.

Outra constatação interessante diz respeito à velocidade em que aparecem os estigmas. Na terra os desgastes se formaram com extrema facilidade e rapidez, ao passo que na madeira somente um brilho muito restrito e esmaecido ocorreu lentamente. Tentando produzir as marcas de uso no corte das árvores, estendemos o número de golpes e consequentemente o tempo, indo num dos ensaios até os 100.000 (cem mil) golpes ao longo de pouco mais de 10 horas e 25 minutos. Todavia, por mais que insistíssemos os macrotraços não se tornavam nítidos. Ao que tudo indica, no arenito silicificado usado para o corte de madeira os estigmas não se fazem visíveis a olho nu. Já para o sílex um escasso brilho conseguiu se formar em torno de um ou dois milímetros além do fio do gume. Contudo, o estilhaçamento causado pelo choque do gume contra a madeira retira completamente este sinal de desgaste de maneira que somente visualizamos um débil brilho formado nos intervalos entre um estilhaçamento e outro (Tab 1).

Pensando em possíveis estilhaçamentos do uso na terra, de maneira esporádica pelo choque com pedras o gume também sofre este tipo de perdas e dele se desprendem lascas maiores. Tais lascas têm a particularidade de levar na sua face superior os macrotraços já fixados. Aliás, há na coleção de Piragiba muitas lascas com a face superior completamente recoberta por um brilho intenso, embotamento forte e estrias expressivas. Todavia, como a velocidade de formação dos estigmas de uso na terra é maior, os negativos destes lascamentos acidentais são rapidamente afetados e neles voltam a se formar as marcas de uso. Aparentemente indesejáveis, tais lascamentos ocasionais reavivam o gume ao mesmo tempo em que o fazem recuar aos poucos, aumentando o seu ângulo. Assim sendo, este desgaste pelos estilhaçamentos e pelos

Tabela 1. Instrumentos experimentais e extensão dos estigmas formados

Table 1. Experimental instruments and extension of the stigmas formed

\begin{tabular}{|l|l|l|l|l|l|l|l|}
\hline Instr & \multicolumn{1}{|c|}{ Mat-Prima } & \multicolumn{1}{c|}{ Uso } & \multicolumn{1}{c|}{ Golpes } & \multicolumn{1}{c|}{ Tempo } & Embot. raio & Brilho & Estrias \\
\hline $11 \mathrm{~B}$ & Arenito fino & Cavar terra & 20.000 & $2 \mathrm{~h} 35^{\prime}$ & $1,5 \mathrm{~mm}$ & $20 \mathrm{~mm}$ & $20 \mathrm{~mm}$ \\
\hline 12 & Arenito grosso & Abater árvore & 100.000 & $10 \mathrm{~h} 25^{\prime} 02^{\prime \prime}$ & - & - & - \\
\hline 15 & Sílex & Cavar terra & 28.000 & $3 \mathrm{~h} 50^{\prime}$ & $0,5 \mathrm{~mm}$ & $38 \mathrm{~mm}$ & $38 \mathrm{~mm}$ \\
\hline 21 & Sílex & Abater árvore & 80.500 & $8 \mathrm{~h} 18^{\prime} 41^{\prime \prime}$ & - & $<2 \mathrm{~mm}$ & - \\
\hline 22 & Granito & Cavar terra & 20.000 & $2{\mathrm{~h} 02^{\prime} 41^{\prime \prime}}^{\prime}$ & $2,5 \mathrm{~mm}$ & $13 \mathrm{~mm}$ & $13 \mathrm{~mm}$ \\
\hline
\end{tabular}


lascamentos acidentais leva o instrumento arqueológico a se esgotar, perdendo volume e massa, até chegar a um ponto em que se torna imprestável para a função projetada, sendo descartado.

Em alguns casos notamos a formação de um brilho difuso numa pequena área restrita e bem delimitada sobre o picoteado do talão e flanco. Tal macrotraço independe da matéria a ser atingida (árvore ou solo), pois resulta do curto atrito dentro do encaixe entre a rocha da lâmina e a madeira do cabo. Entre os espécimes experimentais, uma peça de sílex permitiu as melhores fotos de registro para esse macrotraço oriundo do encabamento, que pode ser comparado com os estigmas de uso nas partes passivas dos instrumentos arqueológicos.

Infelizmente, ainda não dispomos de microscópios apropriados para realizar fotografias que revelem os estigmas traceológicos na plenitude dos seus detalhes. Apenas as fotos $2 b$ e $2 c$ da figura 4, de autoria da Dra. M. Mansur, são de microscópio metalográfico. Todas as demais fotos apresentadas neste artigo são do autor (L. Fernandes) com duas câmeras simples, compactas: - Kodak EasyShare C1013, 10.3 megapixels, zoom óptico de 3x, estabilizador digital de imagem, lentes esféricas equivalentes a 34mm-102mm e - GE A1250, 12.2 megapixels, zoom óptico de $5 x$, estabilizador de imagem, lentes esféricas equivalentes de $5 \times 6,3-$ $31,5 \mathrm{~mm}$. Na tentativa de reverter esta lacuna em 2014, durante um curso de análises microscópicas em artefatos arqueológicos no Centro Austral de Investigaciones Científicas CADIC/CONICET, Ushuaia (Tierra del Fuego - Argentina), em conjunto com a Dra. Mansur, foram analisados e fotografados vários instrumentos arqueológicos e experimentais. Daquelas análises conjuntas constatamos que a superfície dos artefatos arqueológicos sofreu intensa corrosão pósdeposicional, não obstante, são evidentes as áreas polidas por abrasão (brilho) com presença de estrias, além do arredondamento do fio (embotamento). Quanto aos instrumentos experimentais, detectaram-se brilhos e estrias de conformações inquestionáveis entre 50 e 1000 aumentos (Fig 4). Quando usados na terra, além dos estigmas dela resultantes, os instrumentos experimentais ostentam também típicos traços microscópicos do trabalho com matéria vegetal. Ao fim das observações foi possível constatar uma notável convergência entre os estigmas de brilho, estrias e embotamento das experimentações na terra com os mesmos traços visualizados na lâmina lascada arqueológica, provavelmente usada para cavar terra com parcela de resíduos vegetais.

\section{Reconfigurações sobre as lâminas de machado lascadas}

Entendemos (FERNANDES, 2011a, 2014) por reconfiguração a transformação de um instrumento em outro, o que implica o necessário relascamento para se chegar à nova configuração. Tal reaproveitamento é compreensível em contextos de escassez de matériaprima. Contraditoriamente, essa não é a situação prevalente em Piragiba, onde se dá justamente o contrário, ou seja, há uma abundância de rochas acessíveis e aptas ao lascamento. A princípio existem duas maneiras das lâminas de machado lascadas chegarem ao fim das suas vidas úteis: 1. pelo desgaste paulatino decorrente do uso; 2. precocemente, pela ruptura derivada de um acidente de utilização, quando a lâmina lascada se quebra durante um golpe excessivamente forte contra a madeira ou contra a terra. O numeroso acervo do sítio de Piragiba fornece abundantes exemplos de lâminas de machado lascadas descartadas nestas duas condições. Além do mais, permitiu reconhecer o reaproveitamento de lâminas esgotadas ou quebradas para o relascamento e transformação em outros instrumentos, ou seja, a existência de outras cadeias operatórias derivadas que tomam como ponto de partida as lâminas lascadas imprestáveis.

Os indícios que facultaram a identificação de tais relascamentos sobre os objetos descartados remetem: 1. à constância na disposição tecnomorfológica das lâminas de machados lascadas desde a sua produção; 2. somada aos sinais de uso impressos ao longo do tempo e; 3. ocasionalmente, ocorre a formação de uma pátina sobre os negativos da antiga lâmina de machado lascado, em contraste com os negativos do relascamento para a conformação do novo instrumento. Cada um destes 3 níveis de evidência isolados aponta uma fase na cadeia operatória e uma forma do gerenciamento do objeto: $1^{\circ}$ produção; $2^{\circ}$ uso e $3^{\circ}$ retomada ou relascamento. A união dos 3 indicadores dá a noção do estágio evolutivo em que se encontrava a lâmina lascada antes da reconfiguração. Assim, podemos afirmar que o instrumento reconfigurado vem de uma lâmina de machado lascada finalizada e utilizada. Ademais, os estigmas tecnológicos e traceológicos permitem posicionar o utensílio reconfigurado dentro do corpo do antigo instrumento de onde proveio (Fig 5).

A maneira mais direta de compreender as reconfigurações dos instrumentos é observá-las do menor ao maior grau de transformação sobre o suporte, percebido na leitura tecnológica e traceológica. Munidos deste método, reconhecemos cinco reconfigurações: 1. reconfiguração de parte do gume; 2 . de todo o gume; 3. do talão; 4 . do talão e um flanco; 5. reconfiguração sobre grandes lascas das lâminas de machado lascadas.

1. Reconfiguração de parte do gume. Transformação mais facilmente notada, consiste no lascamento de um novo gume sobre o anterior, porém, com características de delineamento distintas. Apesar do relascamento, parte do antigo gume se mantém. É aplicada quase sempre sobre uma lâmina de machado esgotada (Fig 5). 
2. Reconfiguração total do gume. Relascamento de um novo gume com a supressão completa do anterior. Os novos gumes mostram perfis distintos dos anteriores, podendo ser laterais, diagonais ou ter uma ponta destacada (Fig 5).

3. Reconfiguração do talão. Ainda que se mantenha o gume original a lâmina de machado lascada tem o seu talão relascado em um novo gume com os mais diversos delineamentos. Esse segundo gume e a redução do volume, com a consequente desestruturação da parte passiva, tornam claro que a função inicial do instrumento deixa de ser viável.

4. Reconfiguração do talão e um flanco. Nesse nível de transformação a imagem do instrumento original é bastante alterada e para identificá-la é necessário observar atentamente os indicadores tecnológicos e traceológicos. Os novos gumes são lascados removendo-se grande parte ou a totalidade de um dos flancos e do talão, criando contornos que são semicirculares, poligonais ou ainda destacando saliências e reentrâncias marcadas (Fig 5).

5. Reconfigurações sobre grandes lascas das lâminas de machados lascados. Incluímos tal categoria por verificar que as grandes lascas suporte desestruturaram completamente as lâminas de onde foram extraídas, tornando-as imprestáveis como machados lascados. Tratam-se, desta sorte, de casos extremos de identificação das reconfigurações segundo esse método que criamos. Reconfigurações mais extremas certamente existem, todavia, não foram passíveis de reconhecimento. Os novos instrumentos gerados por essa reconfiguração são os mais variados possíveis.

\section{Considerações finais}

Conforme o indicado pelas experimentações, as lâminas de machado lascadas dos sítios da Tradição Aratu investigados não foram utilizadas apenas como machados. Também agiram intensivamente como lâminas de enxadas revolvendo o solo, muito provavelmente para as práticas de cultivo, para abrir as covas dos sepultamentos, para retirar a argila destinada à produção de cerâmica e para muitas outras atividades diárias imprescindíveis à vida em uma populosa aldeia indígena.

Os estigmas traceológicos de uso (embotamento, brilho, estrias) na terra são muito mais evidentes e intensos, formando-se bem mais rápido que os estigmas do corte de madeira. A própria dinâmica do abate de árvores causa constantes estilhaçamentos do gume, removendo os macrotraços de desgaste, fato que acontece em menor escala quando se cava a terra. Desta forma, a não detecção das marcas macroscópicas de uso para o corte de madeira nos artefatos arqueológicos não significa a inexistência de tal utilização. Apenas demonstra que os macrotraços da ação na terra recobrem completamente as marcas menos amplas do trabalho na madeira.

As lâminas de machado lascadas são instrumentos multifuncionais bastante versáteis capazes de desenvolver múltiplas funções. Podem ser mantidas até o fim da vida dentro do projeto inicial para o qual foram idealizadas por intermédio de sucessivos reavivamentos do gume e de eventuais reestruturações que reparem quebras do instrumento. Podem ainda servir de núcleo para a retirada de lascas quando é necessário o uso de um gume mais afiado. Por fim, quando um acidente deixa a lâmina inutilizada, seus restos ainda podem ser transformados em outros instrumentos.

Considerando a hesitação por parte dos arqueólogos brasileiros em reconhecer os estigmas de uso tão ostensivos nas lâminas recolhidas nos sítios e, tendo em conta a facilidade com que as marcas de uso se formaram
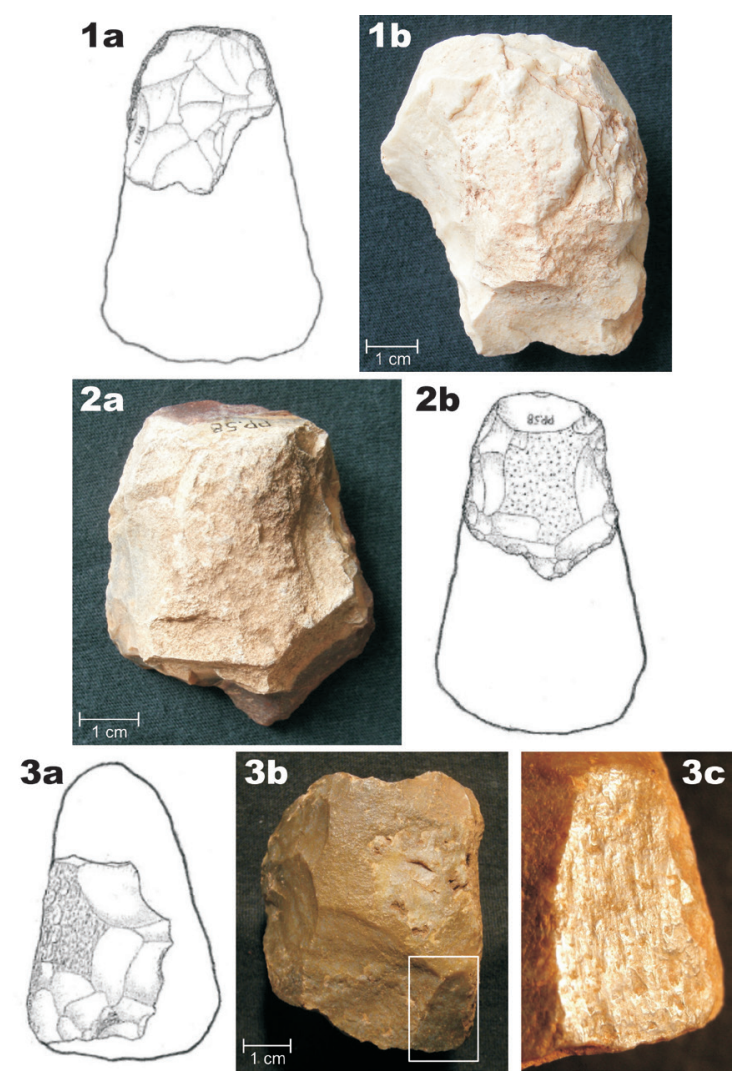

Figura 5. 1ab. Reconfiguração parcial do gume de uma lâmina de machado lascada. 2ab. Reconfiguração total do gume de uma lâmina de machado lascada. 3ab. Reconfiguração do talão e flanco de uma lâmina de machado lascada. 3c. Detalhe ampliado do brilho e estrias remanescentes no gume da antiga lâmina de machado lascada.

Figure 5. 1ab. Partial reconfiguration of the edge of a flaked blade. 2ab. Total reconfiguration of a flaked blade. $3 a b$. Reconfiguration of the butt and flank of a flaked blade. 3c. Enlarged detail of the gloss and remaining striations in edge of the old blade of flaked axe. 
na superfície dos gumes dos instrumentos experimentais, independente do tipo de rocha, acreditamos que existem vários outros utensílios arqueológicos que têm sinais equivalentes guardados em reservas técnicas e expostos em museus. Seria proveitosa uma revisão das coleções no sentido de identificar os artefatos com tais estigmas traceológicos, ampliando o conhecimento sobre as indústrias líticas que representam.

Há uma pesquisa em andamento no Brasil, com a qual colaboramos e que ainda não foi publicada, abordando um sítio da Tradição Aratu em cujo contexto há lâminas de machados polidas que também exibem estimas equivalentes aos aqui apresentados. Ao que tudo indica, mesmo nas superfícies polidas se forma o embotamento, o brilho e as estrias do atrito com a terra de modo muito nítido. Atualmente desenvolvemos experimentações com lâminas de machado polidas, objetivando comparar os resultados com os aludidos instrumentos arqueológicos.

Em suma, o alcance dos resultados até então obtidos conduz a um repensar sobre as denominações cristalizadas pela literatura que associam imediatamente formas a funções. Pelo que constatamos, os ditos machados também cavaram. E, considerando a intensidade e cobertura dos estigmas, cavaram bastante. Nesse sentido, um fato curioso se destaca: a bibliografia etnográfica disponível que conhecemos não aponta nenhum exemplo, alusão ou comentário sobre o uso de instrumentos lascados ou mesmo polidos para revolver o solo ou cavar a terra (é o pau de cavar que cumpre essa função), apesar de comumente citar as lâminas de pedra para o abate de árvores. Estamos diante de uma abertura para revisar as coleções de museus e particulares, tendo em mente formas de uso diversas do então aceito para os tais instrumentos.

Por fim, sublinhamos uma grande ausência por ser preenchida dentro destas pesquisas: a incorporação de estudos num nível óptico mais capazes de diagnósticos precisos quanto ao uso e para a identificação das matérias-primas transformadas pelas lâminas lascadas. A bibliografia internacional produzida a partir do enfoque microscópico para instrumentos lascados é abundante, portanto, pronta para as comparações. Também é de bom alvitre elaborar uma obra de referência com fotografias tomadas ao microscópio de instrumentos experimentais usados para cavar a terra. Desta forma, os aspectos microscópicos dos desgastes provocados pelo atrito de instrumentos lascados e polidos em diferentes rochas com o solo serão colocados ao alcance de pesquisadores do tema.

Salvador - Bahia, Brasil, 26 de março de 2019.

\section{Agradecimentos}

Ao amigo, professor Carlos Costa, pela gentileza na editoração das imagens. Ao geógrafo Helbert Talim pela produção do cartograma da figura 1. Aos vários alunos, que ao longo dos semestres letivos cuidam do processamento dos acervos arqueológicos no laboratório, ultimamente sob os olhares mais atentos da Maiza Sampaio. À Fundação Hansen por permitir a realização das experimentações em suas dependências nas cidades de Cachoeira e São Félix, Bahia.

\section{Bibliografia}

Barkai, R. y R. Yerkes. (2008). Stone Axes as cultural markers: technological, functional and symbolic changes in bifacial tools during the transition from hunter-gatherers to sedentary agriculturalists in the Southern Levant. En, "Prehistoric Technology" 40 years later: functional studies and the Russian legacy, editado por L. Longo y N. Skakun, pp. 159-167. Oxford: BAR S1783, Oxbow.

Boydston, R. (1989). A cost-benefit study of functionally similar tools. En, Time, Energy and Stone Tools, editado por R. Torrence, pp. 67-77. Cambridge University Press, Cambridge.

Calderón, V. (1969). A fase Aratu no Recôncavo e Litoral Norte do Estado da Bahia. Boletim do Museu Paraense Emílio Goeldi (Publicações Avulsas), 13: 161-172.

Calderón, V. (1971). Breve notícia sobre a arqueologia de duas regiões do Estado da Bahia. Boletim do Museu Paraense Emílio Goeldi (Publicações Avulsas), 15: 163-174.

Carneiro, R. (1979). Tree felling with the stone axe: an experiment carried out among the Yanomamö of Southwestern Venezuela. En, Ethnoarchaeology, Implication of Ethnography for Archeology, pp. 21-58. Columbia University Press, Nueva York.

Dourado, D. A. O.; Conceição, A. S.; Silva, J. S. (2013). O gênero Mimosa L. (Leguminosae: Mimosoideae) na APA Serra Branca/Raso da Catarina, Bahia, Brasil. Biota Neotrópica, 13(4): 225-240.

Fernandes, L. A. (2003). Os Sepultamentos do Sítio Aratu de Piragiba - BA. Dissertação de Mestrado Inédita. Salvador, Faculdade de Filosofia e Ciências Humanas: Universidade Federal da Bahia.

Fernandes, L. A. (2011a). As lâminas de machado lascadas Aratu de Piragiba - BA. Tese de Doutorado Inédita. Salvador, Faculdade de Filosofia e Ciências Humanas: Universidade Federal da Bahia.

Fernandes, L. A. (2011b). Elementos das lâminas de machado lascadas de sítios Aratu na Bahia. Habitus, 9(2): 239-257.

Fernandes, L. A. (2012a). Uma revisão da Tradição Aratu 
na Bahia. Clio, 27(1): 1-32.

Fernandes, L. A. (2012b). Macrotraços de uso em instrumento lítico lascado Aratu. Clio, 27(2): 01-19.

Fernandes, L. A. (2014). Possibilidades da análise tecnomorfológica das lâminas de machado lascadas de sítios da tradição Aratu na Bahia. En A. Lourdeau, S. A. Viana e M. J. Rodet, Indústrias líticas na América do Sul: abordagens teóricas e metodológicas (págs. 91-122). Recife: EdUFPE.

Fernandes, L. A. (2017). Pequenas variações dos sepultamentos da Tradição Aratu na Bahia. Especiaria Cadernos de Ciências Humanas, 17(3): 151-172.

Fernandes, L. A. e Nascimento, G. S. (2015). Estigmas de uso em uma lâmina lascada do norte de Minas Gerais. Teoria e Sociedade, 23(1): 73-94.

Fernandes, L. A., Silva, J. P., Nascimento, G. S. (2015). Lâminas lascadas em rochas ígneas de sítios Aratu do Sudoeste da Bahia: traceologia e experimentação. Habitus, 13(2): 17-40.

Gaertner, L. (1994). Determining the function of Dalton adzes from Northeast Arkansas. Lithic Technology, 19(2), 97-109.

Geneste, J., B. Hugues Plisson, C. Clarkson, J. Delannoy, F. Petchey \& R. Whear. (2010). Earliest evidence for groundedge axes: $35,000 \pm 410$ cal BP from Jawoyn country, Arnhem Land. Australian Archaeology, 71, 66-69.

Gnecco, C. \& J. Aceituno. (2004). Poblamiento temprano y espacios antropogénicos en el norte de Suramérica. Complutum, 15, 151-164.

González, E. M. R. (1996a). Os grupos ceramistas pré-coloniais do centro-oeste brasileiro. Revista do Museu de Arqueologia e Etnologia da Universidade de São Paulo, 6: 83-121.

González, E. M. R. (1996b). A ocupação ceramista précolonial do Brasil Central: origens e desenvolvimento. Tese de Doutorado Inédita. São Paulo, Faculdade de Filosofia, Letras e Ciências Humanas: Universidade de São Paulo.

Gónzalez Urquijo, J.E. \& J.J. Ibáñez Estévez (1994). Metodología de análisis funcional de instrumentos tallados em sílex. Universidad de Deusto, Bilbao, Espanha.

Hayden, B. (1989). From chopper to celt: the evolution of resharpening techniques. En Time, Energy and Stone Tools, editado por R. Torrence, pp. 33-43. Cambridge University Press, Cambridge.

Hiscock, P.; S. O'Connor, J. Balme \& T. Maloney. (2016). World's earliest ground-edge axe production coincide with human colonization of Australia. Australian Archaeology, 82(1), 2-11.

Inizan, M.-L.; Reduron, M.; Roche, H.; Tixier, J. (1995). Tecnologia da pedra lascada. Editions du CREP (Traduzido, revisado e ampliado por M. J. Rodet, e J. R. Machado, Belo Horizonte, 2017), Paris, França.

Iversen, J. (1956). Forrest clearence in the Stone Age. Scientific Americans, 194: 36-41

Laming-Emperaire, A. (1967). Guia para o estudo das indústrias líticas da América do Sul: Manuais de Arqueologia. CEPA, Curitiba, Brasil.

Lunardi, A. (2008). Experimental testing with polished green stone axes and adzes. En, "Technology and use", Prehistoric Technology 40 Years Later: Functional Studies and the Russian Legacy, editado por L. Longo y N. Skakun, pp. 369-373. vol. BAR 1783, Oxford, Archaeopress.

Medina, M. E.; Balena, I.; Vázquez, E.; Coriale, N.; Pastor, S. (2019). Bosques, claros y cultivos: uma aproximación tecnológico-funcional a las hachas o azuelas líticas de las Sierras de Córdoba - Argentina. Latin American Antiquity, 30 (1): 142-157.

Mills, P. (1993). An Axe to Grind: Functional Analysis of Anasazi Stone Axes from Sand Canyon Pueblo Ruin (5MT-765), Southwestern, Colorado. Kiva, 58(3), 393-413.

Pawlik, A. (2006). Analysis of two polished stone adzes from Ille Cave at El Nido, Palawan Island, Philippines. Hukay, 10, 38-109.

Politis, G., L. Prates \& I. Pérez. (2008). El Poblamiento de América. Arqueología y Bio-antropología de los Primeros Americanos. Eudeba, Buenos Aires.

Prous, A.; Brito, M. E.; Lima, M. A. (1994). As ocupações recentes no vale do rio Peruaçu (MG). Revista do Museu de Arqueologia e Etnologia, 4: 71-94.

Prous, A.; Costa, F.; Alonso, M. (1996/1997). Arqueologia da Lapa do Dragão. Arquivos do Museu de História Natural - UFMG, 27/28: 139-210.

Rodrigues, F. N. (2016). Hands on! Exploratory Investigation of 'Bumerangóides': A Techno-Functional Approach to the Curved Bifacial Artefacts of South Brazil and Northeast Argentina. Dissetação de Mestrado Inédita. University of Exeter, Inglaterra.

Schmitz, P. I.; Barbosa, A. S.; Miranda, A. F.; Ribeiro, M. B.; Barbosa, M. O. (1996). Arqueologia nos Cerrados do Brasil Central - Sudeste da Bahia e Leste de Goiás: O Projeto Serra Geral. Instituto Anchietano de Pesquisas, São Leopoldo, Brasil. 
Schmitz, P. I.; Wüst, I.; Copé, S. M.; Thies, U. M. E. (1982). Arqueologia do centro-sul de Goiás: uma fronteira de horticultores indígenas no centro do Brasil. Instituto Anchietano de Pesquisas, São Leopoldo, Brasil.

Stroulia, A. (2003). Ground Stone Celts from Franchthi Cave: A Close Look. Hesperia: The Journal of the American School of Classical Studies at Athens, 72(1), 1-30.

Takashi, T. (2012). MIS3 edge-ground axes and the arrival of the first Homo sapiens in the Japanese archipelago. Quaternary International, 248, 70-78.
Toth, N., D. Clark \& G. Ligabuc. (1992). Los últimos fabricantes de hachas de piedra. Investigación y Ciencia, $192,6-11$.

Trías, M. C. (2007). Tallando la piedra: formas, funciones y usos de los útiles prehistóricos. Ariel, Barcelona, Espanha.

Wüst, I. (1883). Aspectos da ocupação pré-colonial em uma área do Mato Grosso de Goiás: tentativa de análise espacial. Dissertação de Mestrado Inédita. São Paulo, Faculdade de Filosofia, Letras e Ciências Humanas: Universidade de São Paulo. 